\title{
Microarray profiling of bone marrow long non-coding RNA expression in Chinese pediatric acute myeloid leukemia patients
}

\author{
LAN CAO $^{1}$, PEI-FANG XIAO ${ }^{1}$, YAN-FANG TAO ${ }^{1}$, SHAO-YAN HU $^{1}$, JUN LU $^{1}$, WEN-LI ZHAO ${ }^{1}$, \\ ZHI-HENG LI $^{1}$, NA-NA WANG ${ }^{1}$, JIAN WANG ${ }^{1}$, XING FENG ${ }^{1}$, YI-HUAN CHAI ${ }^{1}$, \\ JIAN PAN $^{1}$ and GUI-XIONG GU ${ }^{2}$
}

\author{
Departments of ${ }^{1}$ Hematology and Oncology and ${ }^{2}$ Healthcare, \\ Children's Hospital of Soochow University, Suzhou, Jiangsu, P.R. China
}

Received August 7, 2015; Accepted September 26, 2015

DOI: $10.3892 / o r .2015 .4415$

\begin{abstract}
Long non-coding RNA (lncRNA) plays a role in gene transcription, protein expression and epigenetic regulation; and altered expression results in cancer development. Acute myeloid leukemia (AML) is rare in children; and thus, this study profiled lncRNA expression in bone marrow samples from pediatric AML patients. Arraystar Human LncRNA Array V3.0 was used to profile differentially expressed lncRNAs in three bone marrow samples obtained from each pediatric AML patient and normal controls. Quantitative polymerase chain reaction (qRT-PCR) was performed to confirm dysregulated lncRNA expressions in 22 AML bone marrow samples. Gene Ontology (GO) and Kyoto Encyclopedia of Genes and Genomes (KEGG) pathway analyses were performed to construct the IncRNA-mRNA co-expression network. A total of 372 dysregulated lncRNAs (difference $\geq 10$-fold) were found in pediatric AML patients compared to normal controls. Fifty-one mRNA levels were significantly upregulated, while 85 mRNA levels were significantly downregulated by $>10$-fold in pediatric AML, compared to normal controls. GO terms and KEGG pathway annotation data revealed that cell cycle pathway-related genes were significantly associated with pediatric AML. As confirmed by qRT-PCR, expression of 24 of 97 IncRNA was altered in pediatric AML compared to normal controls. In pediatric AML, ENST00000435695 was the
\end{abstract}

Correspondence to: Dr Jian Pan, Department of Hematology and Oncology, Children's Hospital of Soochow University, Suzhou, Jiangsu, P.R. China

E-mail: panjian2008@163.com

Dr Gui-Xiong Gu, Department of Healthcare, Children's Hospital of Soochow University, Suzhou, Jiangsu, P.R. China

E-mail:szggx000@163.com

Key words: lncRNA, microarray profile, pediatric acute myeloid leukemia, quantitative real-time PCR most upregulated lncRNA, while ENST00000415964 was the most downregulated IncRNA. Data from this study revealed dysregulated lncRNAs and mRNAs in pediatric AML versus normal controls that could form gene pathways to regulate cell cycle progression and immunoresponse. Further studies are required to determine whether these lncRNAs could serve as novel therapeutic targets and bbdiagnostic biomarkers in pediatric AML.

\section{Introduction}

Acute myeloid leukemia (AML) is the most common form of acute leukemia that occurs more frequently in adults, but relatively rare in children; and AML incidence increases with age (1). AML is characterized by the rapid growth of abnormal white blood cells that accumulates in the bone marrow, which inhibits production and differentiation of normal blood cells $(1,2)$. Genetically, AML is defined as a clonal disorder caused by malignant transformation of bone marrow-derived cells, self-renewing stem cells, or progenitors that demonstrate a decreased rate of self-destruction and aberrant differentiation (3). Pediatric AML comprises of up to $20 \%$ of all childhood leukemia (4). Although overall AML prognosis has been improved in the last decade, further development and identification of prognostic markers or novel targets for AML treatment could improve the survival rate of AML patients, especially pediatric AML patients.

Long non-coding RNA (lncRNA) regulates gene transcription and protein expressions genetically and epigenetically, and altered expressions result in cancer development. Human genomic data has shown that $\sim 75 \%$ of the human genome is transcribed into RNA, and only a few above $1 \%$ codes protein expressions; indicating that a large portion of the genome is dedicated as regulators $(5,6)$. Many 1 ncRNAs ranging from 0.2 to 100 kilobases $(\mathrm{kb})$ in length are transcribed from the genome. Among these newly discovered RNA elements, lncRNAs have been identified to have functional roles in a diverse range of cellular functions such as development, differentiation, cell fate, as well as disease pathogenesis (7-11). Expression analyses of cancer versus normal cells have 
revealed aberrant non-coding RNA (ncRNA) expression in various human cancers. For example, an altered PCGEM1 expression was associated with increased proliferation and colony formation in prostate cancer cells (12). MALAT1, also known as NEAT2, was originally identified as an abundantly expressed ncRNA during metastasis of early-stage non-small cell lung cancer; and its overexpression is a prognostic marker for poor patient survival rate $(13,14)$. MALAT1 was also found to be highly expressed in hepatocellular carcinoma (15-17). The oncofetal H19 gene was the first imprinted ncRNA to be identified, and loss of imprinting (LOI) at chromosome 11p15.5H19/IGF2 locus leads to an imbalanced expression of H19 and IGF2. H19 dysregulation has been implicated in a variety of human cancers such as colorectal (18), HCC (19), breast $(20)$, and bladder cancers $(21,22)$.

Various lncRNAs were reported to be implicated in malignant hematopoiesis associated with blood cell neoplasms such as leukemia $(23,24)$. H19 ncRNA was highly expressed in Bcr-Abl-transformed cell lines and primary cells derived from patients in a Bcr-Abl kinase-dependent manner (23). IncRNA MONC and MIR100HG were highly expressed in acute megakaryoblastic leukemia blasts (24). Thus, lncRNAs may be useful as diagnostic and prognostic markers in leukemia. In the present study, we profiled differential expression of lncRNAs in pediatric AML to better understand AML pathogenesis and identify biomarkers and novel therapeutic targets.

\section{Materials and methods}

Patients and samples. Bone marrow specimens were obtained from 22 pediatric AML patients at the Department of Hematology and Oncology, Children's Hospital of Soochow University, between 2011 and 2014. This study was approved by the Ethics Committee of the Children's Hospital of Soochow University (\#SUEC2011-021 and \#SUEC2014-037), and written informed consent was obtained from all parents or guardians. AML diagnosis was made in accordance with the revised French-American-British (FAB) classification (25). The main clinical and laboratory features of this cohort of patients are summarized in Table I. Additionally, bone marrow samples from 20 donors without leukemia were used as controls. Bone marrow mononuclear cells (BMNCs) were isolated using Ficoll solution within $2 \mathrm{~h}$ after bone marrow samples were harvested, and subjected for isolation of total cellular RNA.

Profiling of lncRNA expression using Arraystar Human LncRNA Array V3.0. Arraystar Human LncRNA Array V3.0 was used to profile expression of lncRNAs, which was performed by KangChen Bio-tech (Shanghai, China) according to a previous study (26). Briefly, RNA samples from BMNCs were further purified to remove rRNA, and transcribed into fluorescent cRNA as probes to hybridize to the Human LncRNA Array V3.0 (8660 K; Arraystar). The array contains 30,586 lncRNAs and 26,109 coding transcripts, which were collected from the most authoritative databases (such as RefSeq, UCSC, Knowngenes, and Ensembl) and related literature. Array data were then analyzed by MultiExperiment Viewer software for upregulation or downregulation of lncRNA expression in AML samples compared to control samples with a cut-off point of 2 -fold for upregulation and a cut-off point of 0.5 -fold for downregulation.

Gene Ontology and Kyoto Encyclopedia of Genes and Genomes pathway analyses. Gene Ontology (GO) functionally analyzes differentially expressed genes with GO categories (http://david.abcc.ncifcrf.gov/summary.jsp). Pathway analysis of differentially expressed genes was performed based on the latest Kyoto Encyclopedia of Genes and Genomes (KEGG) database (http://www.genome.jp/kegg). Differentially expressed genes and gene product enrichment with particular attention to GO biological processes and molecular functions were grouped into gene pathways using a p-value $\leq 0.05$, as shown below.

Construction of the lncRNA-mRNA co-expression network. The construction of the IncRNA-mRNA co-expression network included three steps: i), lncRNA screening: lncRNAs that were upregulated or downregulated with a fold-change $>3.0$ and a p-value $<0.05$ were first selected to enhance data reliability. Sequences of 1 ncRNAs that have not been recorded in ENCODE were removed. ii), IncRNA-miRNA interactions were predicted by miRcode (http://www.mircode. org/). iii), mRNAs targeted by miRNAs with experimental support were obtained from TarBase (http://www.microrna. gr/tarbase).

Network construction procedures included the following: i), preprocessing of data: if one coding gene has different transcripts, the median value was taken to represent the value of this gene expression without special treatment of lncRNA expression values; ii), data were screened and subset of data were removed according to the lists of differential lncRNA and mRNA expressions obtained from GO and KEGG pathway analyses; iii), Pearson's correlation coefficient was calculated, and the $\mathrm{R}$ value was used to calculate the correlation coefficient between lncRNA and coding genes; and iv), Pearson's correlation coefficient was used for screening, wherein, RNAs with a Pearson's correlation coefficient $\geq 0.98$ were considered significant. The IncRNA-mRNA co-expression network was then constructed by Cytoscape software (The Cytoscape Consortium, San Diego, CA, USA).

RNA isolation and $q R T-P C R$. Total cellular RNA was isolated from bone marrow samples using a TRIzol reagent (Invitrogen, Carlsbad, CA, USA) and stored at $-80^{\circ} \mathrm{C}$ until use. RNA concentration was determined using a spectrophotometer (NanoDrop 2000) and purity was assessed by agarose gel electrophoresis. RNA samples were then reversely transcribed into cDNA using $4 \mu \mathrm{g}$ of RNA samples in a $10-\mu 1$ volume and SuperScript II reverse transcriptase (Invitrogen) according to manufacturer's protocols. For qPCR, we first designed PCR primers according to the database of Real-time primers (Center for Medical Genetics, http://medgen.ugent. be/CMGG/) or using the online program, Primer 3 (www. fokker.wi.mit.edu/primer3/input.htm). Primer selection parameters were set to primer size: $20-26$ nts; primer melting temperature: $60-64^{\circ} \mathrm{C}$; GC clamp: 1 ; and product size range: generally $120-240 \mathrm{bp}$, which went down to $100 \mathrm{bp}$ if no appropriate primers could be identified. Primers were synthesized by Invitrogen. The qPCR amplification was set in a $20-\mu 1$ 
Table I. The main clinical and laboratory features of the pediatric AML samples.

\begin{tabular}{|c|c|c|c|c|c|c|c|}
\hline & Gender & $\begin{array}{c}\text { Age } \\
\text { (years) }\end{array}$ & Diagnosis & $\begin{array}{l}\text { AML } \\
\text { typing }\end{array}$ & Chromosome analysis & Fusion gene & Mutation \\
\hline 1 & $\mathrm{~F}$ & 11 & AML & M5 & $\begin{array}{c}46, \mathrm{XX}, \mathrm{t}(9 ; 11)(\mathrm{P} 22 ; \mathrm{q} 23) \\
{[9] / 46, \mathrm{XX}[3]}\end{array}$ & MLL/AF9 & \\
\hline 2 & $\mathrm{~F}$ & 5 & AML & M5 & ns & ns & \\
\hline 3 & M & 7 & AML & $\mathrm{M} 2 \mathrm{a}$ & $46, X Y$ & AML/ETO & \\
\hline 4 & M & 5 & AML & $\mathrm{M} 2 \mathrm{a}$ & $46, X Y$ & $(-)$ & CEBPA TAD1 \\
\hline 5 & $\mathrm{~F}$ & 6 & AML & M4 & $46, \mathrm{XX}$ & dupMLL, FLT-TKD & \\
\hline 6 & M & 6 & AML & M2 & $\begin{array}{c}45, \mathrm{X},-\mathrm{Y}, \mathrm{t}(8 ; 21)(\mathrm{q} 22 ; \mathrm{q} 22) \\
{[7] / 46, \mathrm{XY}[5]}\end{array}$ & AML1/ETO & \\
\hline 7 & $\mathrm{~F}$ & 12 & AML & AML & $46, \mathrm{XX}$ & AML/ETO & \\
\hline 8 & M & 2 & AML & M5 & $46, X Y$ & $46, \mathrm{XY}$ & \\
\hline 9 & $\mathrm{~F}$ & 10 & AML & M2 & $46, \mathrm{XX}, \mathrm{t}(8 ; 21)(\mathrm{q} 22 ; \mathrm{q} 22)$ & AML/ETO & C-Kit \\
\hline 10 & M & 5 & AML & M4 & $46, \mathrm{XY}$ & $(-)$ & \\
\hline 11 & $\mathrm{~F}$ & 2 & AML & M5 & ns & ns & \\
\hline 12 & $\mathrm{~F}$ & 13 & AML & M3 & $46, X X, t(15 ; 17)(q 22 ; q 21)$ & PML/RARA & \\
\hline 13 & M & 12 & AML & M2a & ns & ns & \\
\hline 14 & $\mathrm{~F}$ & 2 & AML & M4 & $46, \mathrm{XX}$ & CBF/MYH11 & \\
\hline 15 & M & 4 & AML & M2 & $46, X Y$ & AML/ETO & \\
\hline 16 & $\mathrm{~F}$ & 12 & AML & M2 & $\begin{array}{c}45, X,-X, t(8: 21)(q 22 ; q 22) \\
{[6] / 46, X X[2]}\end{array}$ & AML/ETO & C-Kit \\
\hline 17 & M & 6 & AML & M3 & $\begin{array}{c}46, X Y, t(15: 7)(q 22: q 210 \\
{[9] / 46, X Y[3]}\end{array}$ & PML/RARA & \\
\hline 18 & M & 8 & AML & $\mathrm{M} 2 \mathrm{a}$ & $46, \mathrm{XY}$ & $(-)$ & \\
\hline 19 & $\mathrm{~F}$ & 1 & AML & M5b & $46, X X, t(6 ; 11)(q 27 ; q 23)$ & MLL/AF6 & \\
\hline 20 & M & 10 & AML & M4 & $47, X Y,+22, \operatorname{inv}(16)(p 13 q 22)$ & CBF/MYH11 & \\
\hline 21 & M & 9 & AML & $\mathrm{M} 2 \mathrm{a}$ & $46, X Y$ & $(-)$ & \\
\hline 22 & M & 7 & AML & M3 & $46, X Y$ & PML/RARA & \\
\hline
\end{tabular}

reaction volume containing $1 \mu 1$ of cDNA, $0.2 \mathrm{mM}$ of each primer, and $10 \mu \mathrm{l}$ of SYBR Green Mix (Roche, Indianapolis, IN, USA); and was performed in a LightCycler 480 (Roche) using universal thermal cycling parameters (an initial $95^{\circ} \mathrm{C}$ for $10 \mathrm{~min}$ and $45 \mathrm{cycles}$ of $15 \mathrm{sec}$ at $95^{\circ} \mathrm{C}, 15 \mathrm{sec}$ at $60^{\circ} \mathrm{C}$, and $60 \mathrm{sec}$ at $72^{\circ} \mathrm{C}$. After that, the melting curve for $10 \mathrm{sec}$ at $95^{\circ} \mathrm{C}$ and $60 \mathrm{sec}$ at $65^{\circ} \mathrm{C}$ ). For gene expression levels, we used the comparative $\mathrm{Ct}$ method. First, gene expression levels for each sample were normalized to the expression level of the housekeeping gene encoding glyceraldehyde 3-phosphate dehydrogenase (GAPDH) within a given sample $(-\Delta \mathrm{Ct})$; and the relative expression of each gene was calculated with $10^{6} \mathrm{x} \log 2(-\Delta \mathrm{Ct})$. The difference between pediatric AML samples compared to control samples was used to determine $10^{6} \mathrm{x} \log 2(-\Delta \mathrm{Ct})$.

Statistical analysis. SPSS v11.5 (SPSS Inc., Chicago, IL, USA) was used for all statistical analyses. Differentially expressed IncRNAs in AML samples were statistically compared with normal controls, and a cut-off point of 2-fold for upregulation and 0.5-fold for downregulation of lncRNA expressions were used in AML samples. For gene expression, we performed a Student's t-test; and a p-value $\leq 0.05$ was considered statistically significant.

\section{Results}

Differentially expressed lncRNAs and mRNAs in pediatric $A M L$. The Arraystar Human LncRNA 8x60k V3.01 microarray was used to profile differentially expressed lncRNAs and mRNAs in pediatric AML versus normal controls. A total of 2,335 differently expressed mRNAs were found in pediatric AML (Fig. 1A and B). Among them, 51 mRNAs were significantly upregulated and 85 mRNAs were significantly downregulated for $>10$-fold in pediatric AML compared to normal controls. Clustering analysis was used to visualize the relationships between the mRNA expression patterns present in the samples (fold-changes $\geq 10$; Fig. $1 C$ and D).

Moreover, a total of 2,413 differentially expressed lncRNA were identified in pediatric AML (Fig. 2A and B). Hierarchical clustering analysis of these differentially expressed lncRNAs with $>10$-fold difference is shown in Fig. 2C and D and Tables II and III.

Altered lncRNA-related gene pathways in pediatric AML. Ontological pathway enrichment analysis was performed on differentially expressed lncRNA and mRNA, and a biological process enrichment analysis was performed using the DAVID tool to gain insights into their functions (GEO 
A

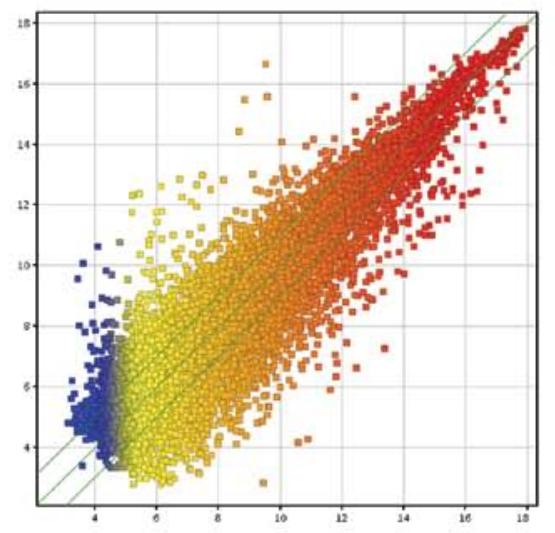

B

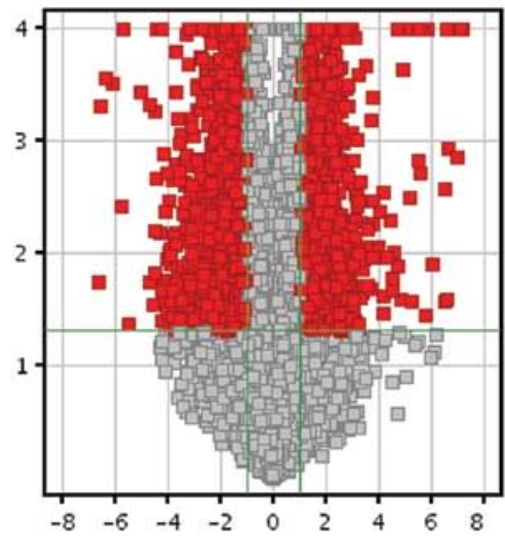

C
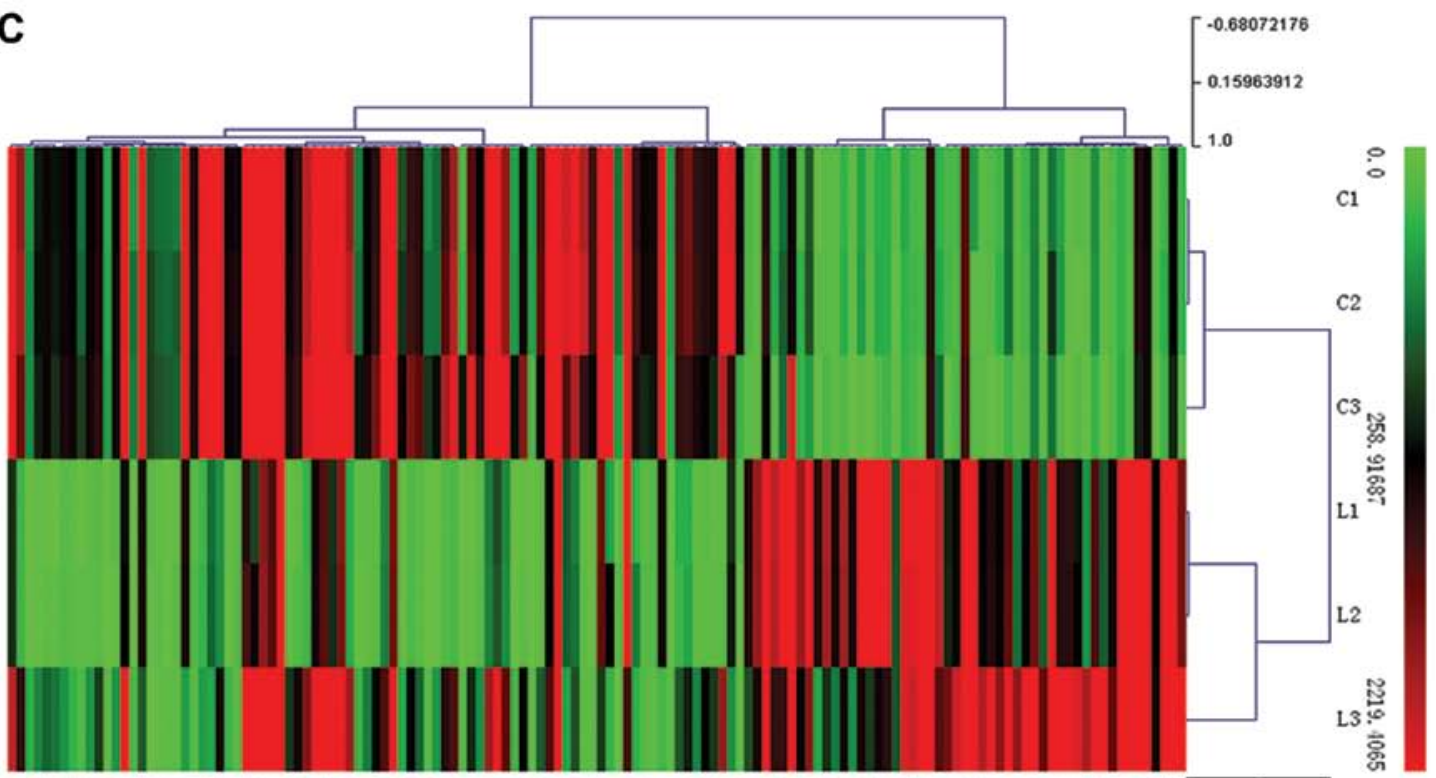

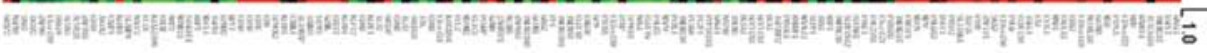
密

D

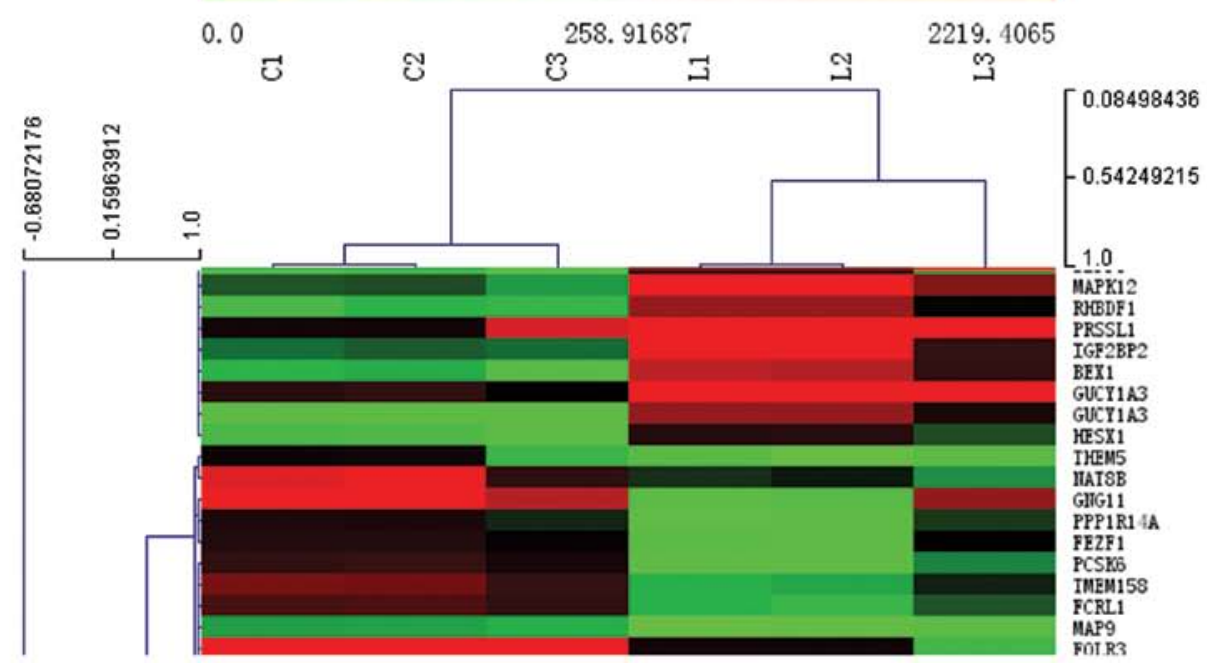

Figure 1. Cluster analysis of differentially expressed mRNAs in pediatric acute myeloid leukemia (AML). The Arraystar Human LncRNA 8x60k V3.01 microarray was utilized to profile and identify differentially expressed mRNAs in pediatric AML compared to normal controls. (A and B) Scatter-Plot assessment of mRNA expression is shown between pediatric AML and normal controls. Green lines are fold-change lines (the default fold-change value given is 2.0). The mRNAs above the top green line and below the bottom green line indicated a $>2.0$ fold-change of mRNAs between the two compared samples. (C) Hierarchical clustering analysis of the 136 significantly dysregulated mRNAs with $\geq 10$ fold-changes in pediatric AML compared to normal controls. (D) Partial amplification of hierarchical clustering analysis of the 136 significantly dysregulated mRNAs with $\geq 10$ fold-changes in pediatric AML compared to normal controls. 
A

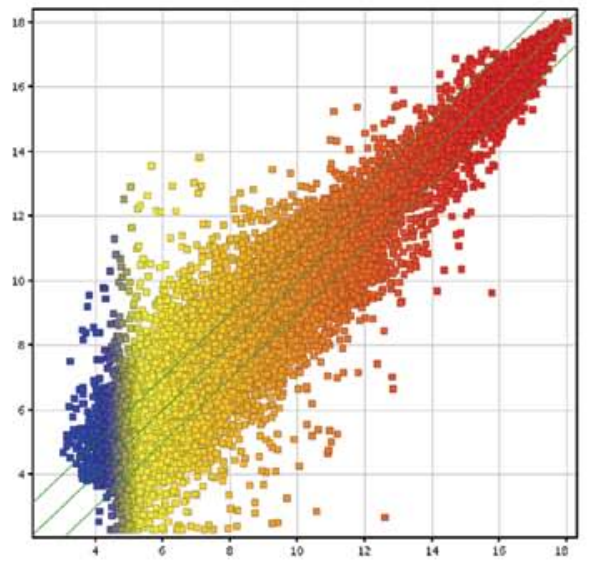

B

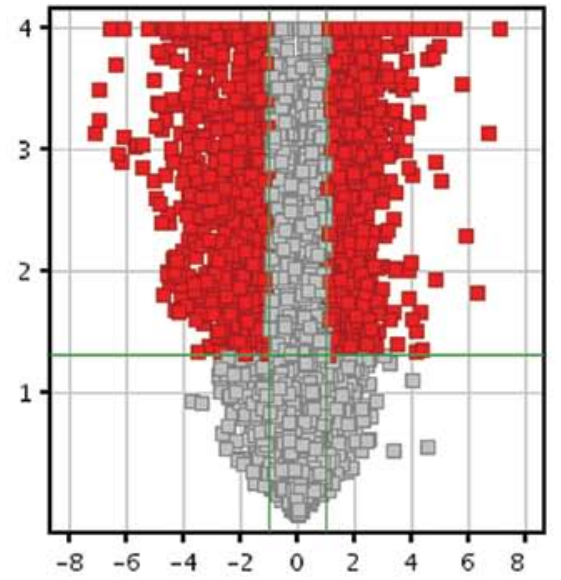

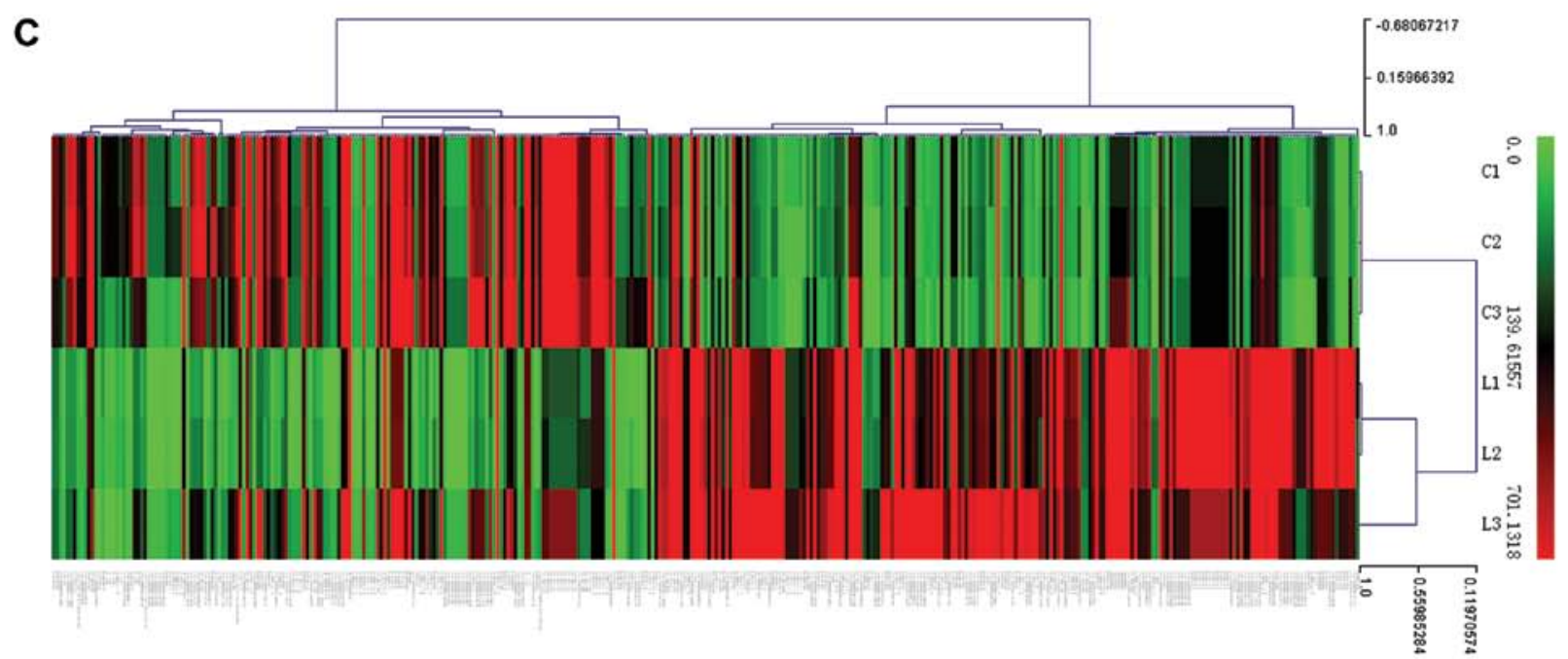

D

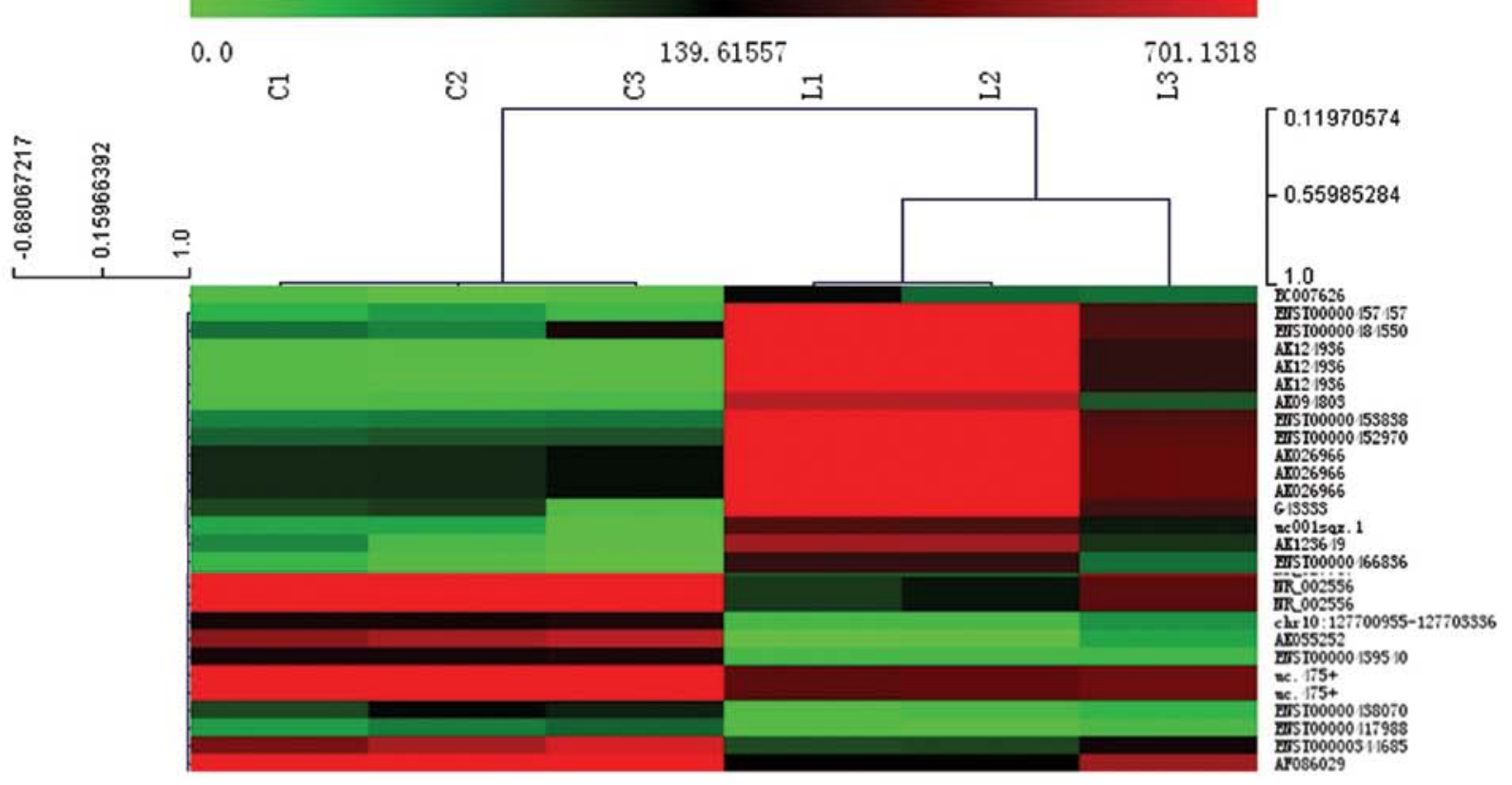

Figure 2. Cluster analysis of differentially expressed lncRNAs in pediatric acute myeloid leukemia (AML) is shown. (A and B) Scatter-Plot assessment of lncRNA expression is shown between pediatric AML and normal controls. Green lines are fold-change lines (the default fold change value given is 2.0). The lncRNAs above the top green line and below the bottom green line indicated a $>2.0$ fold-change of lncRNAs between AML and normal samples. (C) Hierarchical clustering analysis of the 372 significantly dysregulated lncRNAs for $\geq 10$ fold-changes in pediatric AML compared to normal controls. (D) Partial amplification of hierarchical clustering analysis of the 372 significantly dysregulated lncRNAs for $\geq 10$ fold-change in pediatric AML compared to normal controls. 


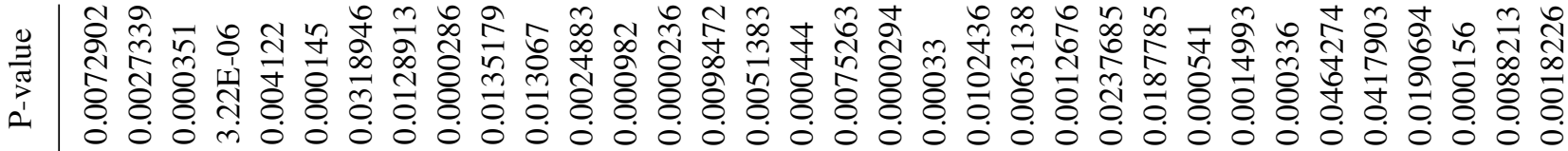

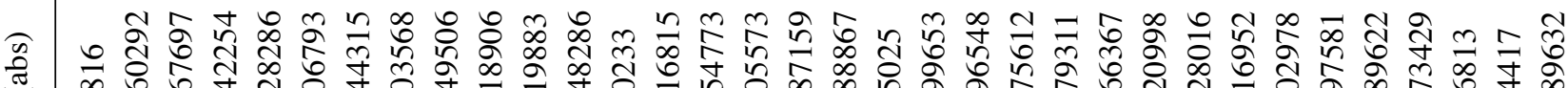

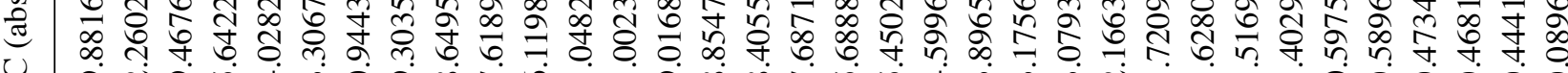
रें

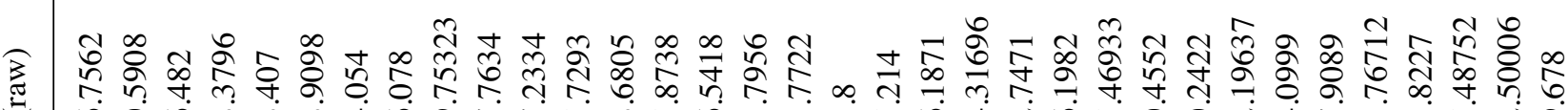
凷

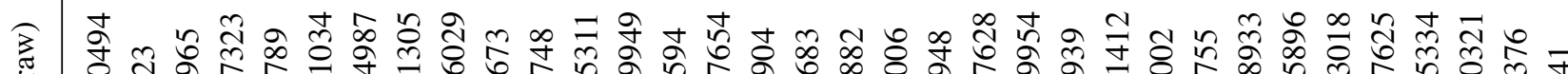
矛

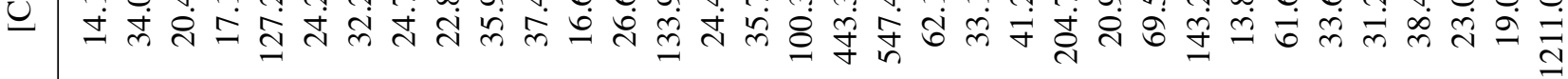

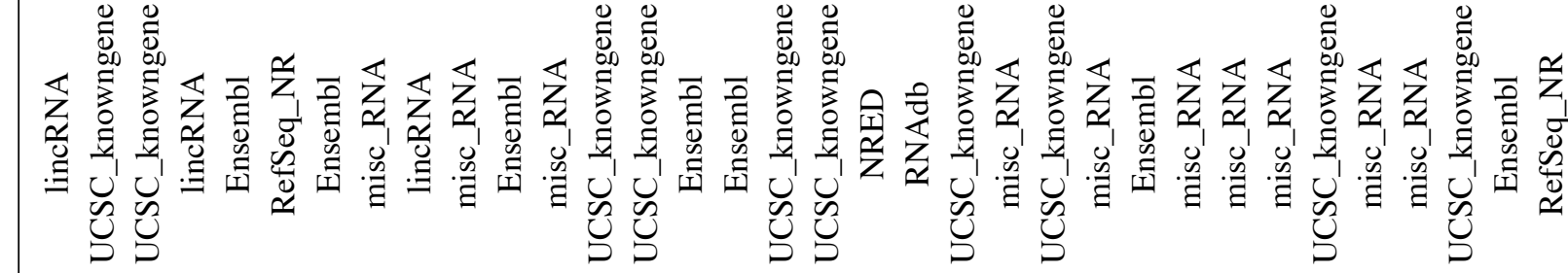

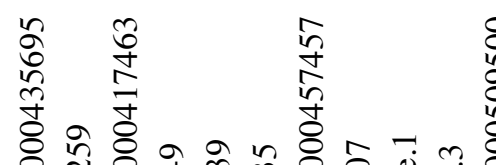<smiles>[C]1C=[Ge]C1</smiles>

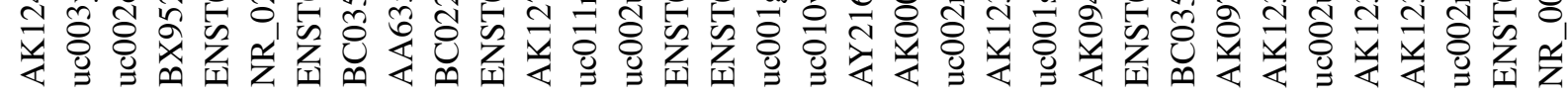




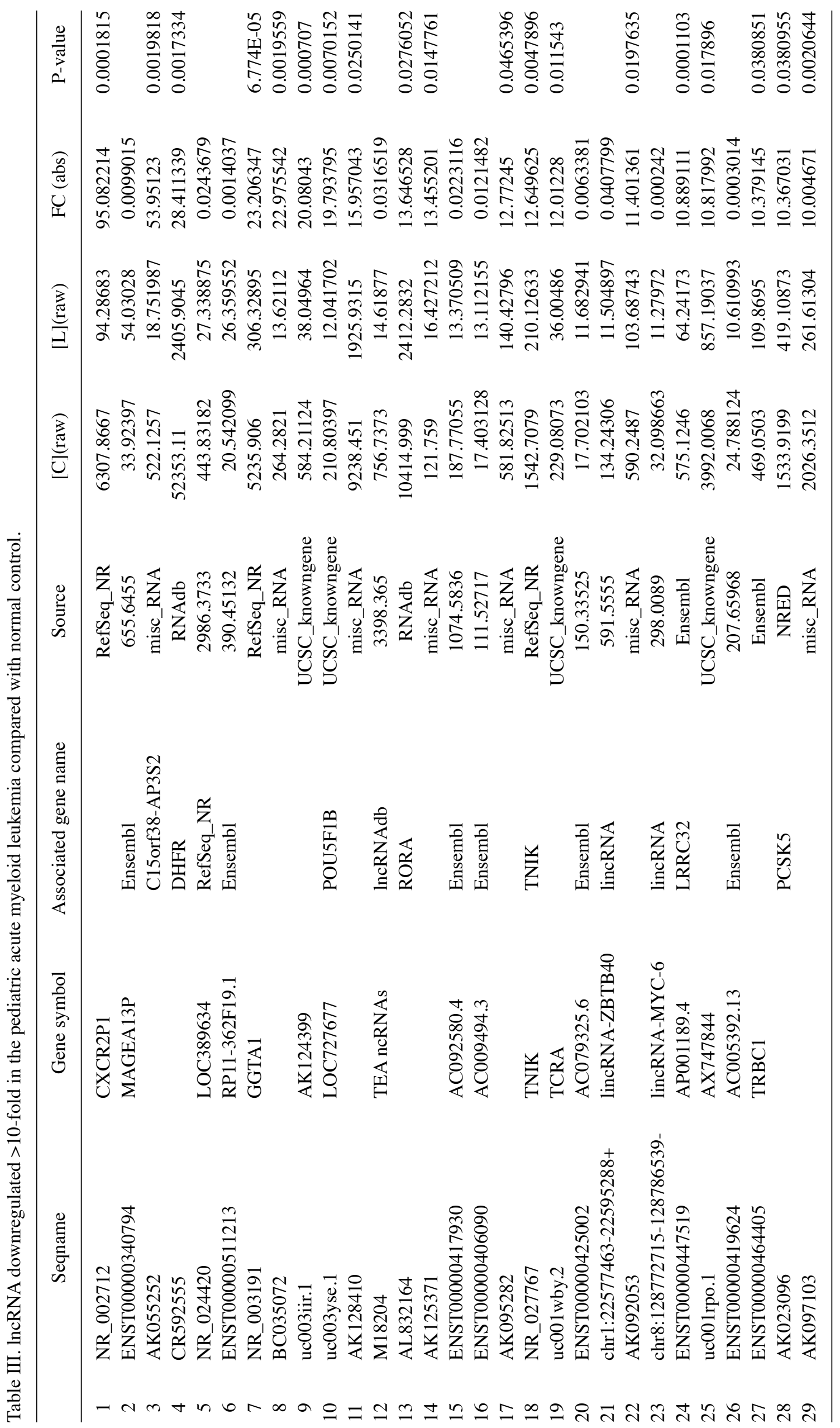


A

C

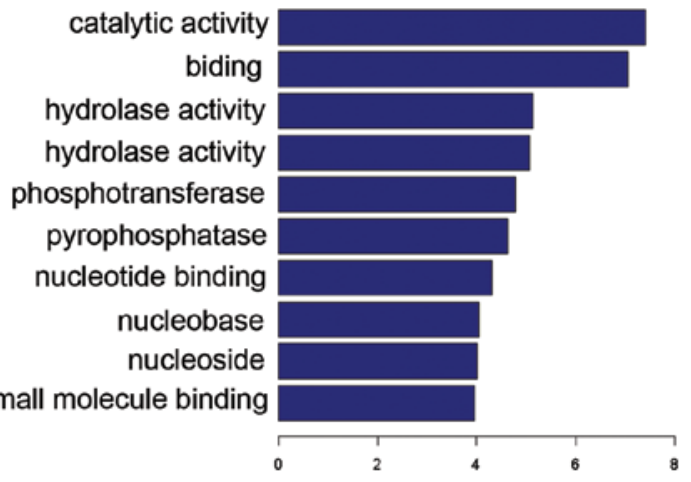

Enrichment score (-log10(P value)) organelle fission mitosis nuclear division cell division

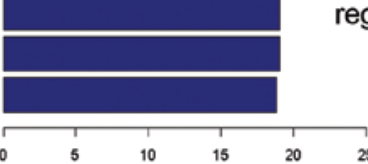

B

immune response immune system process biological regulation signal transduction regulation of biological response to stimulus

T cell activation regulation of immune response cell communication defense response

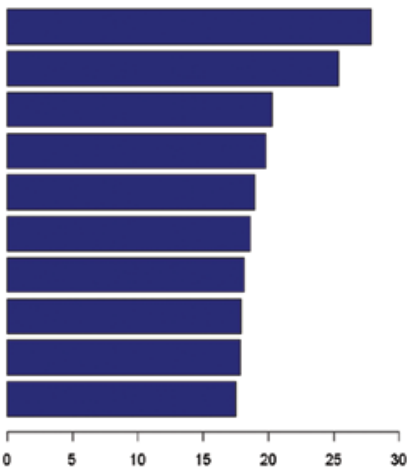
Enrichment score (-log10(P value))

D

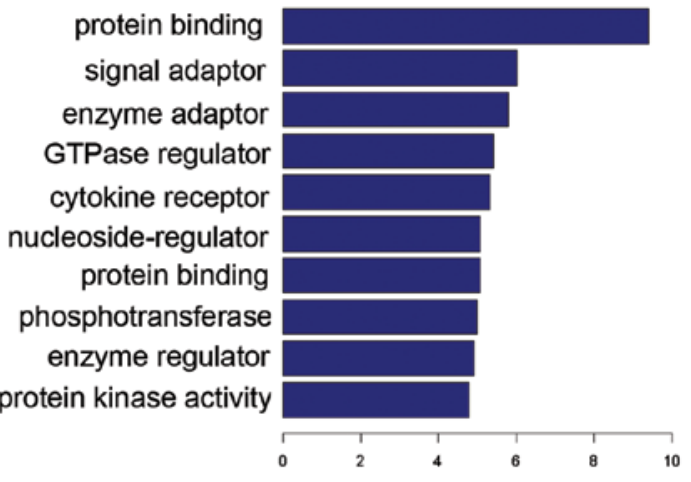

Enrichment score (-log10(P value))

E

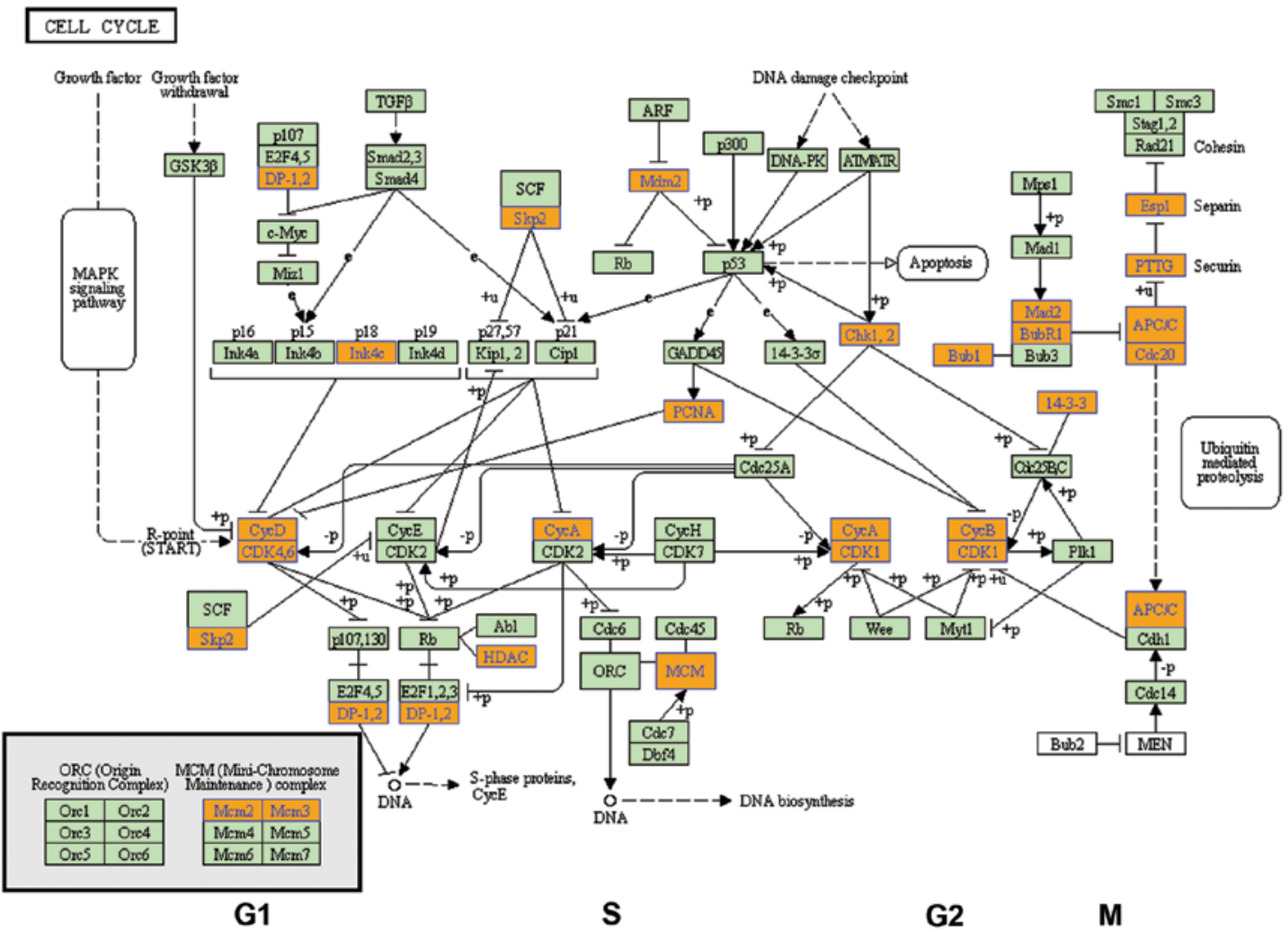

Figure 3. Gene Ontology (GO) and Kyoto Encyclopedia of Genes and Genomes (KEGG) pathway analysis of differentially expressed mRNAs in pediatric acute myeloid leukemia (AML). (A) The most enriched GO terms targeted by upregulated transcripts were involved in a variety of functions. (B) The most enriched GO terms targeted by downregulated transcripts were involved in a variety of functions. (C) The most significant molecular function (MF) enrichment scores for upregulated transcripts. (D) The most significant MF enrichment scores for downregulated transcripts. (E) KEGG pathway annotations of the most enriched cell cycle pathways with a p-value of $7.22764 \mathrm{E}^{-10}$. Cell cycle pathway proteins included ANAPC11, ANAPC13, ANAPC7, BUB1,BUB1B, CCNA2, $C C N B 1$ and $C C N B 2$. 


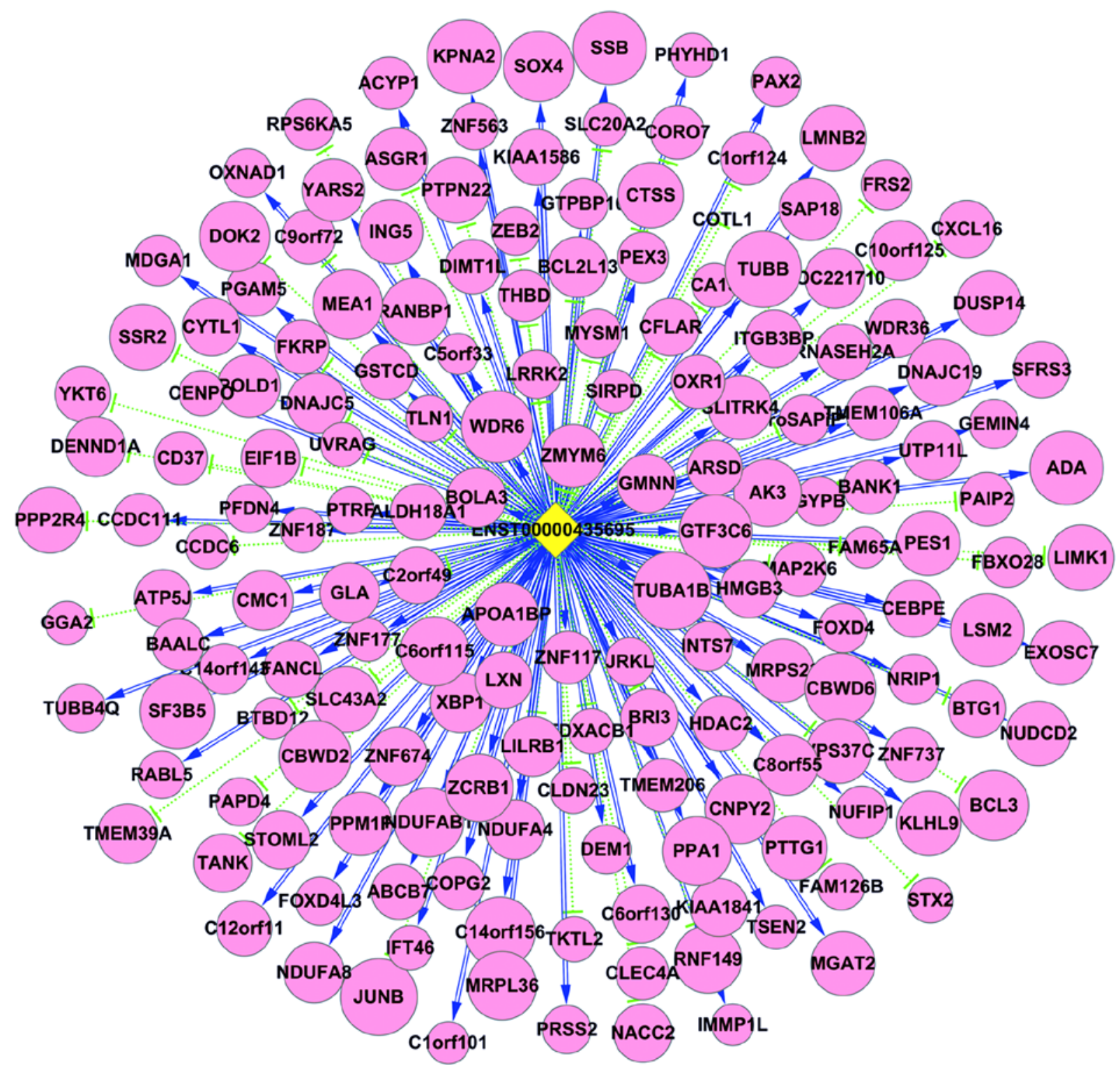

Figure 4. The lncRNA-mRNA co-expression network. Pearson's correlation coefficient was calculated using the R value to estimate the correlation coefficient between lncRNA ENST00000435695 and coding genes. A Pearson's correlation coefficient value $\geq 0.98$ was considered a significant correlation of the IncRNA-mRNA co-expression network. Data were analyzed and constructed by Cytoscape software (The Cytoscape Consortium, San Diego, CA, USA). This co-expression network suggests an inter-regulation of lncRNAs and mRNAs in acute myeloid leukemia development.

accession no. GSE64975). The most enriched GO targeted by upregulated and downregulated transcripts were involved in cell cycle regulation, immune response, and immune system process (Fig. 3A and B). The most significant molecular function (MF) enrichment scores are shown in Fig. 3C and D. KEGG annotations of the most enriched pathways are shown in Fig. 3E, and KEGG pathway annotations of the most enriched pathways were cell cycle regulation with a p-value $<7.22764 \mathrm{E}^{-10}$. Cell cycle pathway proteins included ANAPC11, ANAPC13, ANAPC7, BUB1, BUB1B, CCNA2, $C C N B 1$ and $C C N B 2$.

lncRNA/mRNA co-expression network in pediatric AML. Next, we constructed a coding and non-coding gene expression network based on the correlation analysis between differentially expressed lncRNAs and mRNAs. Pearson's correlation coefficient analysis was performed using a coefficient no less than 0.98 to construct the network (Fig. 4). The expression network indicated that one mRNA or IncRNA may correlate with one to tens of lncRNAs. The co-expression network may suggest the inter-regulation of lncRNAs and mRNAs during AML development.

Confirmation of dysregulated lncRNAs in pediatric AML versus normal control samples. To confirm the microarray data, we selected 97 dysregulated lncRNAs from the microarray analysis of 22 pediatric AML samples and 20 control samples using qRT-PCR. Our data revealed that the lncRNA expression profile in pediatric AML was significantly different from normal controls (Fig. 5A). A total of 20 genes were successfully clustered using lncRNA samples (Fig. 5B). A total of 24 lncRNAs were confirmed to be dysregulated in pediatric AML (Table IV), and detailed expressions of each upregulated and downregulated lncRNA in pediatric AML are shown in 
A

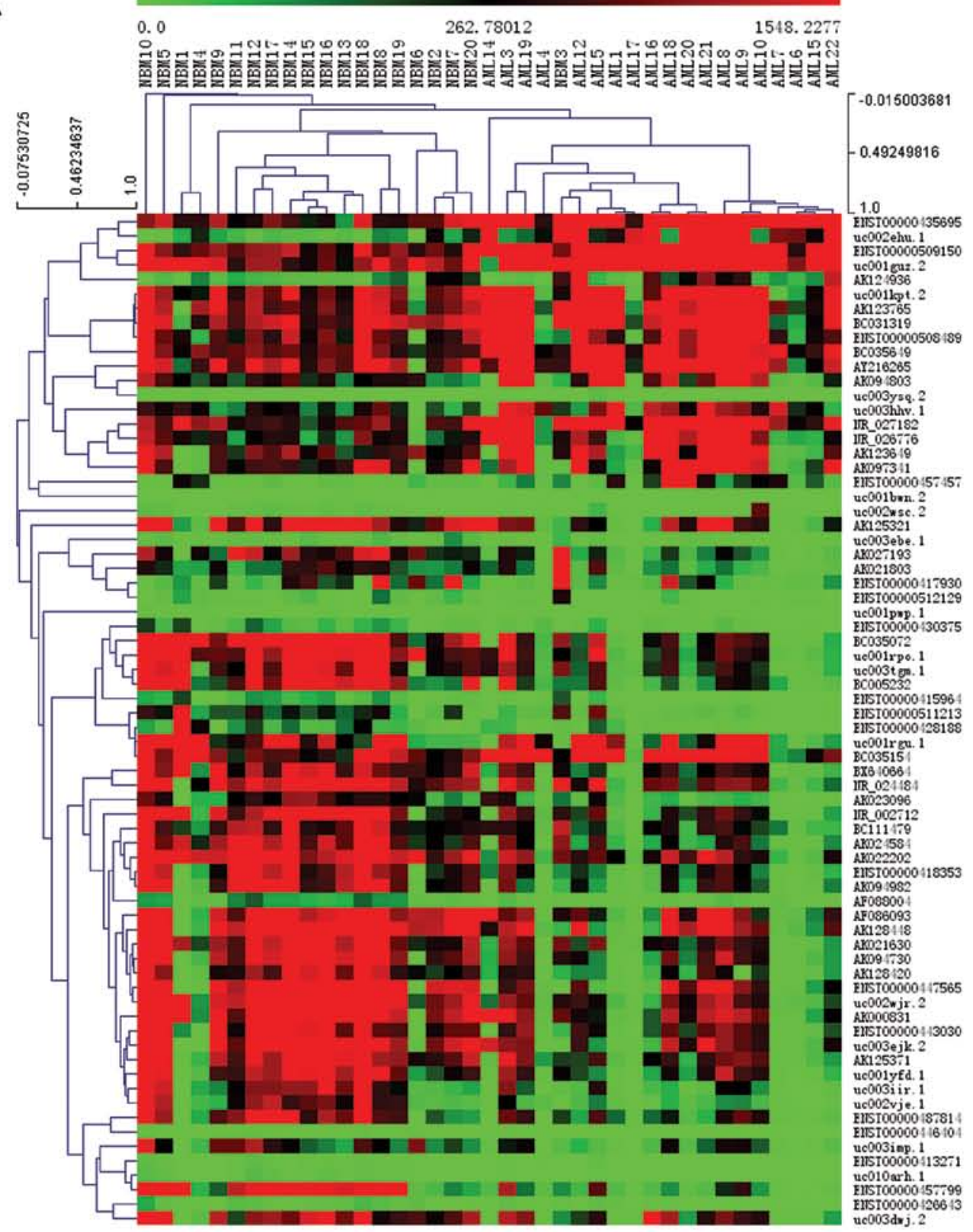

B

$0.0 \quad 777.1926$

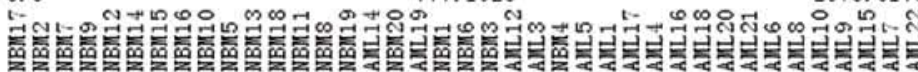

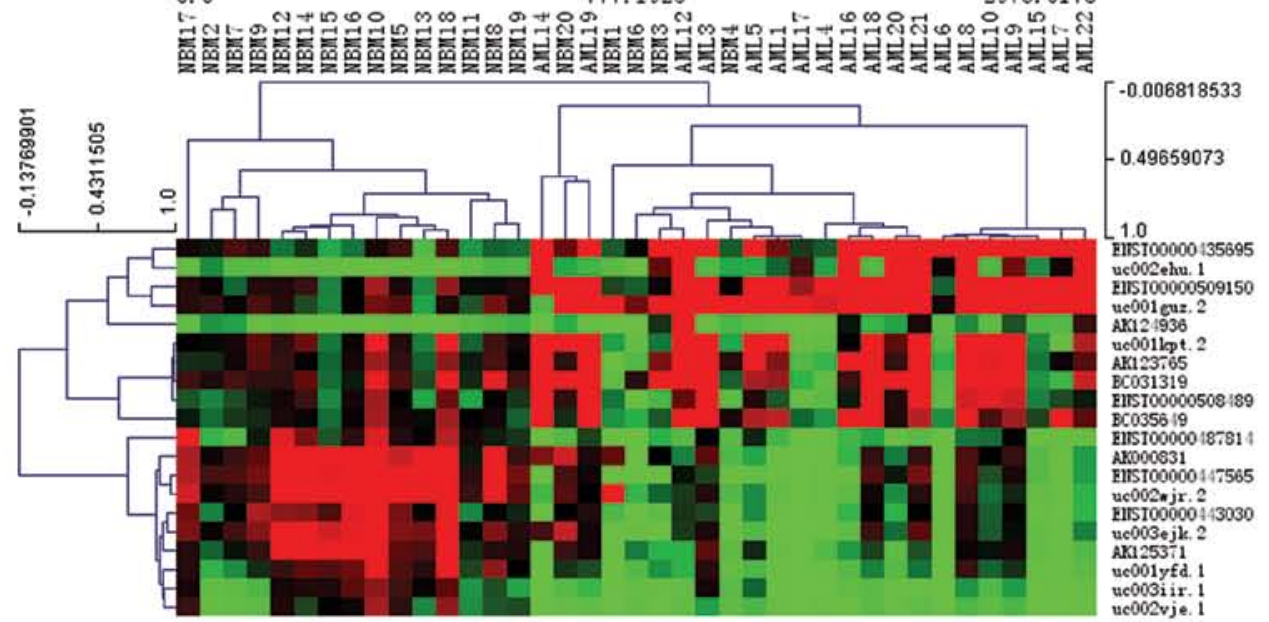

Figure 5. Verification of differentially expressed lncRNAs in pediatric acute myeloid leukemia (AML) vs. normal control samples. (A) Cluster analysis. lncRNA expression between AML samples and normal control samples were analyzed using qRT-PCR and MultiExperiment View (MEV) cluster software. (B) Twenty lncRNAs were successfully clustered between AMLs and normal controls. 
Table IV. IncRNAs most dysregulated in the pediatric acute myeloid leukemia compared with normal control.

\begin{tabular}{rlcccc}
\hline & \multicolumn{1}{c}{ Seqname } & $\mathrm{N}$ & AML & FC & P-value \\
\hline 1 & ENST00000435695 & 991.3334 & 65836.24647 & 66.41181 & 0.001962 \\
2 & uc002ehu.1 & 157.1266 & 9872.330406 & 62.83042 & 0.040465 \\
3 & ENST00000509150 & 1056.795 & 41764.2482 & 39.51973 & 0.026976 \\
4 & uc001guz.2 & 2078.731 & 76903.56747 & 36.99544 & 0.00817 \\
5 & ENST00000457457 & 41.08492 & 1197.166609 & 29.13883 & 0.021802 \\
6 & uc001kpt.2 & 1255.126 & 25614.56252 & 20.40796 & 0.027621 \\
7 & NR_027182 & 878.2717 & 9092.321414 & 10.35252 & 0.008923 \\
8 & AK123765 & 1042.844 & 9066.866062 & 8.694369 & 0.014631 \\
9 & BC031319 & 1911.99 & 15009.11256 & 7.849995 & 0.021456 \\
10 & AK124936 & 104.2268 & 612.3396304 & 5.87507 & 0.017449 \\
11 & uc003hhv.1 & 283.4595 & 1530.759093 & 5.400274 & 0.043802 \\
12 & NR_026776 & 394.2164 & 2050.126185 & 5.20051 & 0.008692 \\
13 & AK027193 & 816.4939 & 105.3354471 & 0.129009 & 0.000302 \\
14 & AK024584 & 1589.484 & 203.7112857 & 0.128162 & 0.000796 \\
15 & BC005232 & 1683.387 & 213.9596056 & 0.127101 & 0.000347 \\
16 & AK094982 & 1550.97 & 196.5648444 & 0.126737 & 0.009100 \\
17 & uc003ebe.1 & 18.21419 & 2.279349604 & 0.125141 & 0.013112 \\
18 & ENST0000512129 & 41.8703 & 4.359070151 & 0.104109 & 0.008417 \\
19 & AF088004 & 63.27258 & 6.537745743 & 0.103327 & 0.000117 \\
20 & uc002vje.1 & 610.3662 & 48.49298993 & 0.079449 & 0.001854 \\
21 & uc010arh.1 & 6.662799 & 0.504782 & 0.075761 & 0.006096 \\
22 & ENST00000428188 & 247.9221 & 18.21257952 & 0.073461 & 0.001850 \\
23 & ENST0000045799 & 2389.248 & 169.9657438 & 0.071138 & 0.000823 \\
24 & ENST00000415964 & 56.81532 & 3.721491039 & 0.065502 & 0.000550 \\
\hline & & & & &
\end{tabular}

Figs. 6 and 7. The most upregulated lncRNA in pediatric AML is ENST00000435695 and the most downregulated lncRNA in pediatric AML is ENST00000415964.

\section{Discussion}

Our present study profiled differentially expressed lncRNAs and mRNAs in pediatric AMLs. We demonstrated for the first time the expression profiles of human lncRNAs in pediatric AML by microarray; and identified a collection of aberrantly expressed lncRNAs in pediatric AML compared to normal controls. It is likely that these dysregulated lncRNAs play a key or partial role in the development and/or progression of pediatric AML. Previous genome-wide profiling studies revealed that many transcribed non-coding ultra conserved regions exhibit distinct profiles in various human cancers. For example, a genome-wide RNA sequencing (RNAseq) analysis evaluated the differential expressions of lncRNAs in a cohort of 102 prostate cancer versus benign samples (27); and identified 121 unannotated transcripts that could accurately discriminate benign, localized and metastatic samples. Other IncRNA expression profile studies were conducted in $>100$ paired esophageal squamous cell carcinoma and normal samples (28), 5 pairs of liver cancer and normal tissues (29), and 6 pairs of renal clear cell carcinoma and corresponding normal tissues (26); which revealed large numbers of lncRNAs that were significantly dysregulated in cancer tissues. Recent studies have started to reveal the importance of lncRNAs in leukemia tumorigenesis. For example, IncRNA H19 was highly expressed in Bcr-Abl-transformed cell lines and primary cells derived from patients in a Bcr-Abl kinase-dependent manner (23). IncRNA MONC and MIR100HG were highly expressed in acute megakaryoblastic leukemia blasts (24). However, it remains to be determined how these lncRNAs participate and contribute to leukemia development or progression. In this study, we found that some of these differentially expressed lncRNAs regulated cell cycle progression and immunosystem functions. Future study is required to investigate whether manipulating lncRNA expressions could control AML progression and be used as a therapeutic target to control AML.

Our present study profiled and identified a group of dysregulated lncRNAs and mRNAs in bone marrow samples obtained from pediatric AML patients versus normal controls. We also verified 97 lncRNAs in >20 AML and normal control samples; and found 24 dysregulated lncRNAs in pediatric AML. These lncRNAs could regulate cell cycle progression and immunoresponses that could be associated with AML development or progression. Further study is required to determine whether these lncRNAs may serve as new therapeutic targets and diagnostic markers for pediatric AML. 


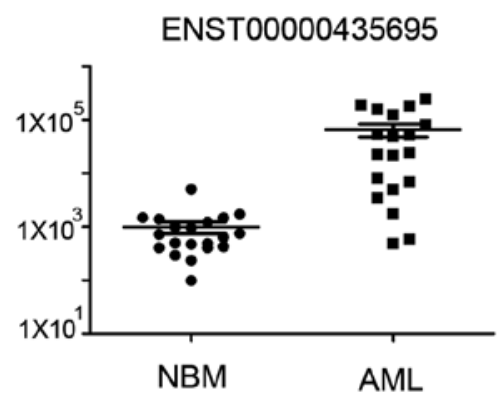

uc001guz.2

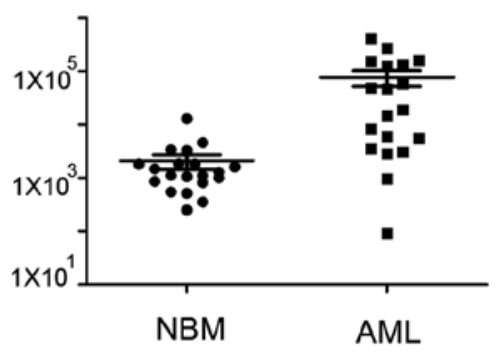

NR_027182

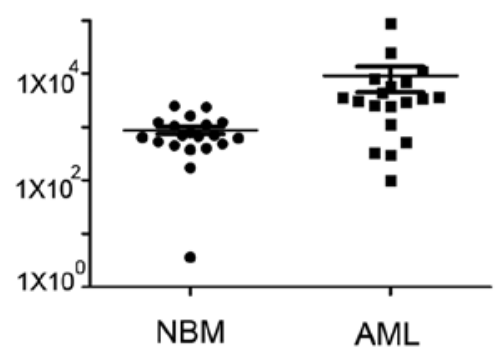

AK124936

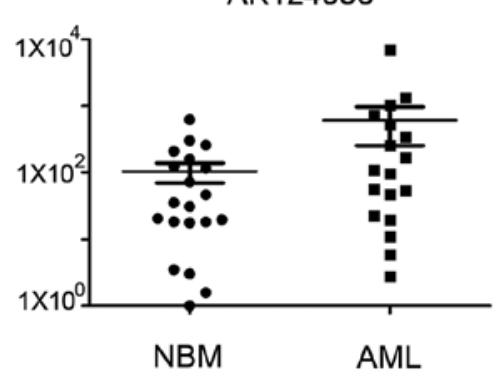

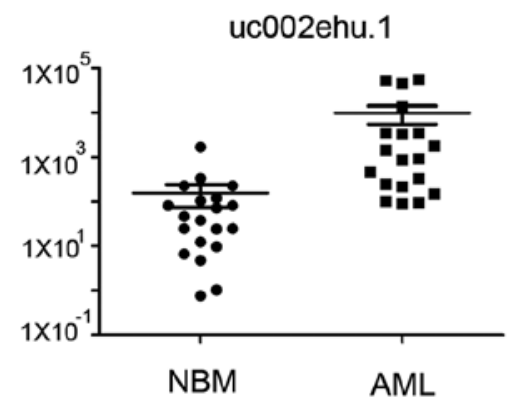

ENSTO0000457457

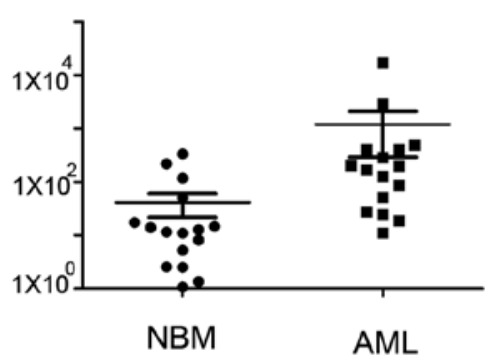

AK123765

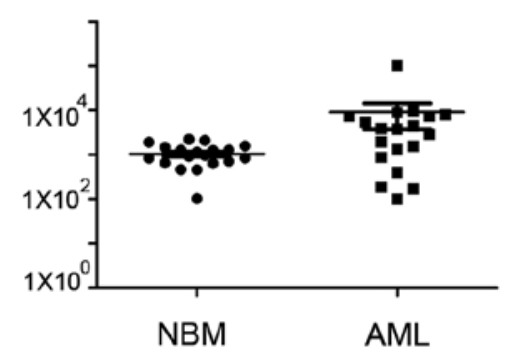

uc003hhv.1

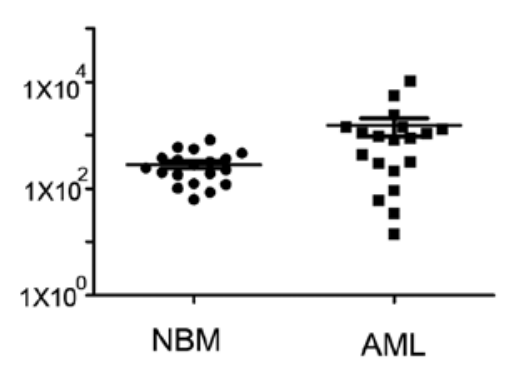

ENST00000509150

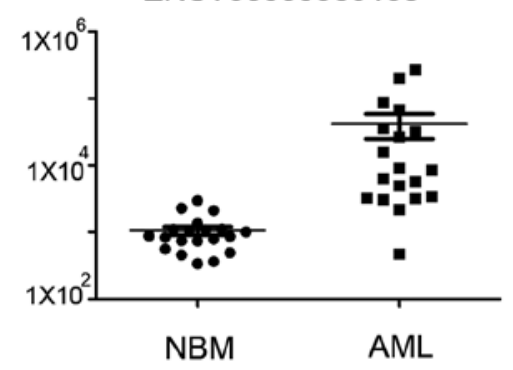

uc001kpt. 2

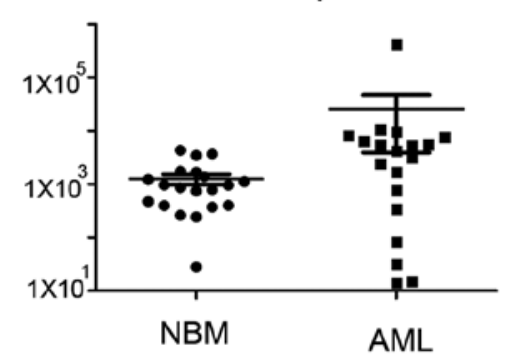

BC031319

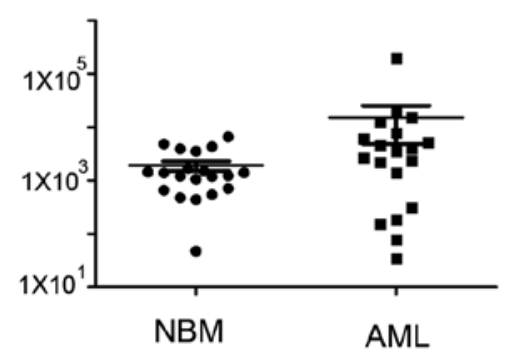

NR_026776

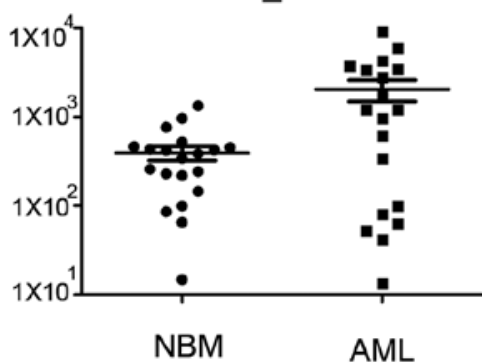

Figure 6. Verification of upregulated lncRNA expression in pediatric acute myeloid leukemia (AML). Expression of pediatric AML samples vs. control samples was analyzed using qRT-PCR, and summarized as mean average \pm standard error (SE). $P<0.05$ was considered statistically significant.

\section{Acknowledgements}

The present study was supported in part by grants from the National '12th Five-Year' Major Science and Technology fund (\#2011ZX09302-007-01), the National Natural Science Foundation of China (nos. 81100371, 81370627, 81300423 and 81272143), the Key Medical Subjects of Jiangsu Province (\#XK201120), the Key Laboratory of Suzhou (\#SZS201108 and \#SZS201307), the Suzhou Science and Technology Development Planning 2013 Projects (\#SYS201352), the Suzhou City Youth Science and Technology Projects (\#KJXW2012021), and the
Technological Special Project for 'Significant New Drugs Creation' (\#2012ZX09103301-040). The funders had no role in study design, data collection and analysis, decision to publish, or preparation of the manuscript.

\section{References}

1. Appelbaum FR, Baer MR, Carabasi MH, Coutre SE, Erba HP, Estey E, Glenn MJ, Kraut EH, Maslak P, Millenson M, et al; National Comprehensive Cancer Network: NCCN practice guidelines for acute myelogenous leukemia. Oncology (Williston Park) 14: 53-61, 2000. 
ENST00000415964

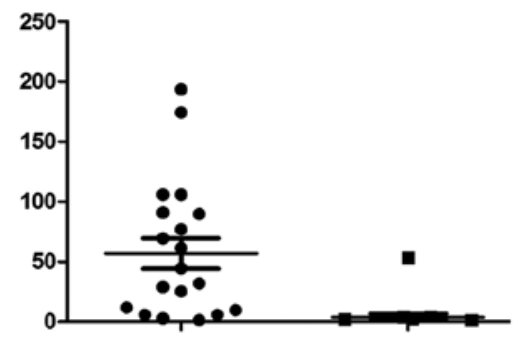

NBM

AML uc010arh.1

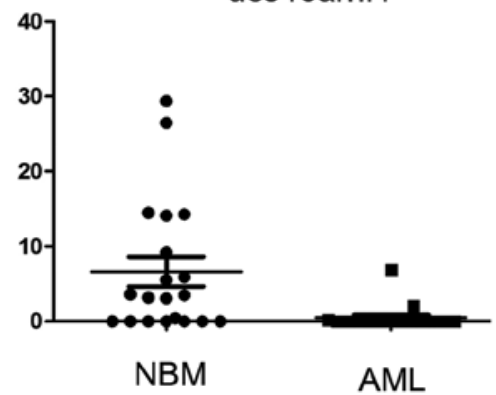

ENST00000512129

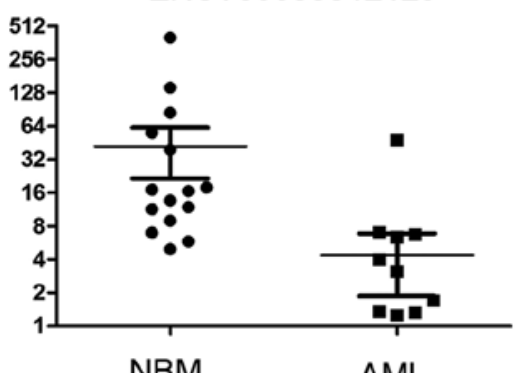

AML

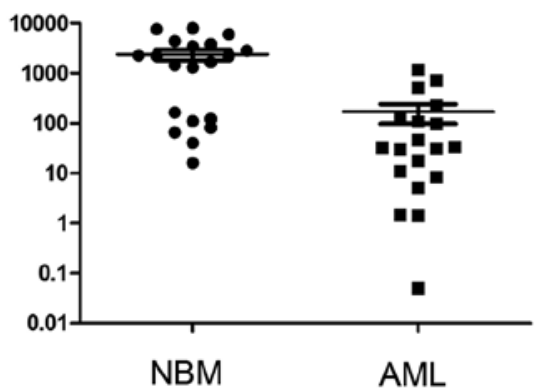

ENST00000428188

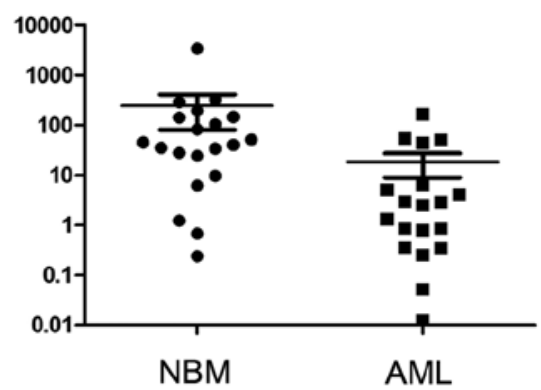

uc002vje.1
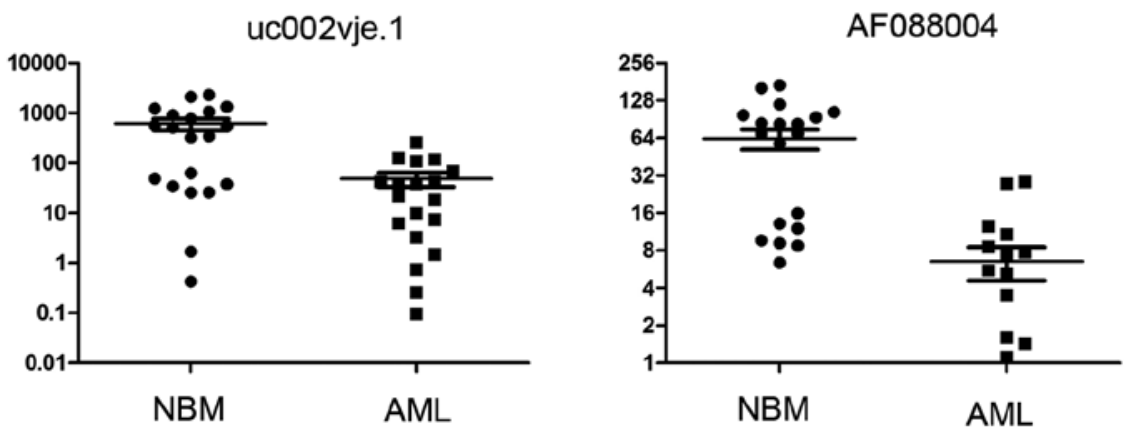

uc003ebe.1
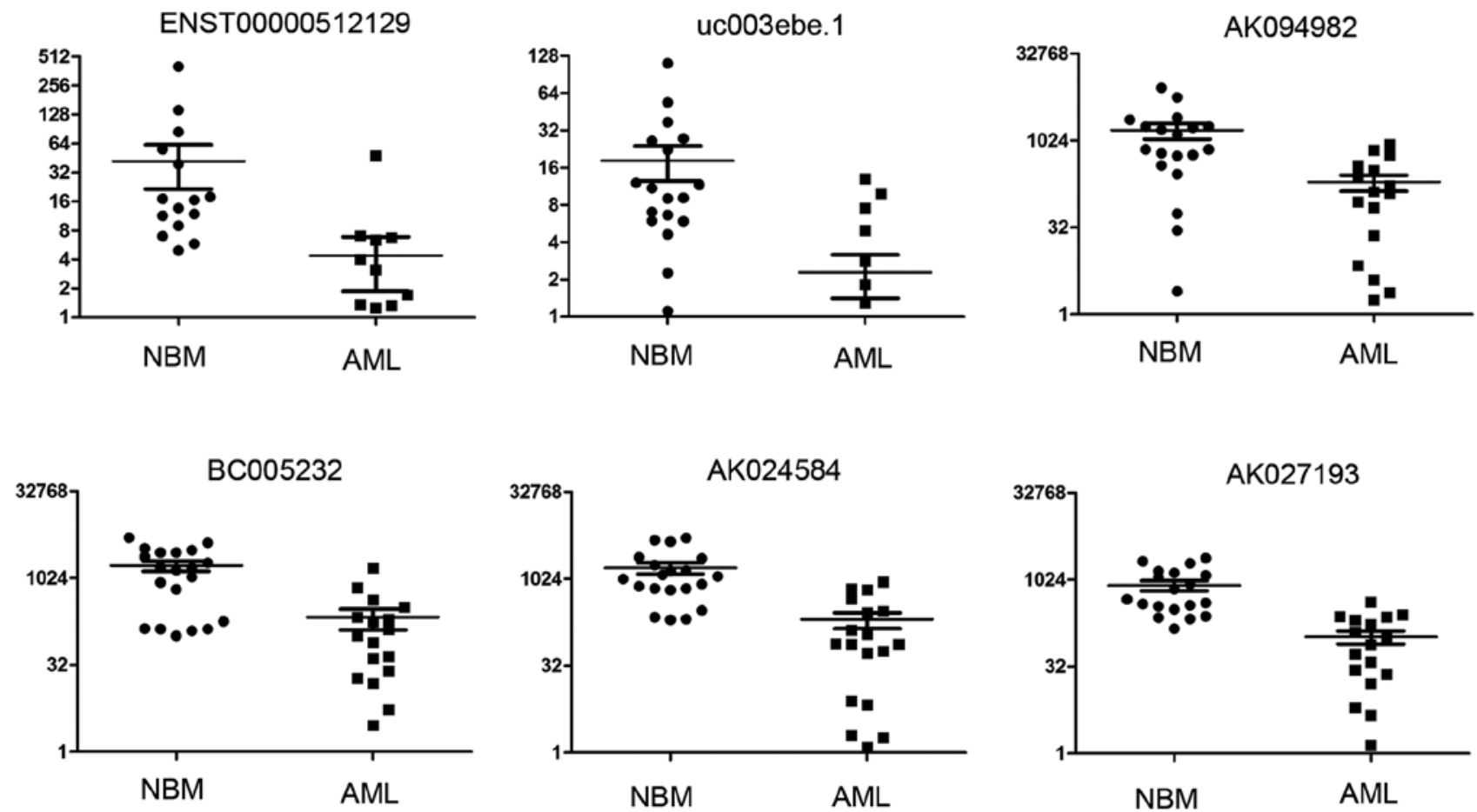

Figure 7. Verification of downregulated lncRNA expression in pediatric acute myeloid leukemia (AML). Expression of pediatric AML samples vs. control samples were analyzed using qRT-PCR, and summarized as mean \pm standard error $(\mathrm{SE})$. $\mathrm{P}<0.05$ was considered statistically significant.

2. Sanz GF, Sanz MA, Vallespí T, Cañizo MC, Torrabadella M, García S, Irriguible D and San Miguel JF: Two regression models and a scoring system for predicting survival and planning treatment in myelodysplastic syndromes: A multivariate analysis of prognostic factors in 370 patients. Blood 74: 395-408, 1989.

3. Hope KJ, Jin L and Dick JE: Human acute myeloid leukemia stem cells. Arch Med Res 34: 507-514, 2003.

4. Hasle H, Niemeyer CM, Chessells JM, Baumann I, Bennett JM, Kerndrup G and Head DR: A pediatric approach to the WHO classification of myelodysplastic and myeloproliferative diseases. Leukemia 17: 277-282, 2003.
5. Song X, Wang X, Arai S and Kurokawa R: Promoter-associated noncoding RNA from the CCND1 promoter. Methods Mol Biol 809: 609-622, 2012.

6. Zhang X, Lian Z, Padden C, Gerstein MB, Rozowsky J, Snyder M, Gingeras TR, Kapranov P, Weissman SM and Newburger PE: A myelopoiesis-associated regulatory intergenic noncoding RNA transcript within the human HOXA cluster. Blood 113: 2526-2534, 2009.

7. Rinn JL: lncRNAs: Linking RNA to chromatin. Cold Spring Harb Perspect Biol 6: 6, 2014. 
8. Rinn JL and Chang HY: Genome regulation by long noncoding RNAs. Annu Rev Biochem 81: 145-166, 2012.

9. Chen Z, Jia S, Li D, Cai J, Tu J, Geng B, Guan Y, Cui Q and Yang J: Silencing of long noncoding RNA AK139328 attenuates ischemia/reperfusion injury in mouse livers. PLoS One 8: e80817, 2013

10. Yin Z, Guan D, Fan Q, Su J, Zheng W, Ma W and Ke C: lncRNA expression signatures in response to enterovirus 71 infection. Biochem Biophys Res Commun 430: 629-633, 2013.

11. Kung JT, Colognori D and Lee JT: Long noncoding RNAs: Past, present, and future. Genetics 193: 651-669, 2013.

12. Fu X, Ravindranath L, Tran N, Petrovics G and Srivastava S: Regulation of apoptosis by a prostate-specific and prostate cancer-associated noncoding gene, PCGEM1. DNA Cell Biol 25 135-141, 2006

13. Gutschner T, Hämmerle $M$ and Diederichs S: MALAT1 - a paradigm for long noncoding RNA function in cancer. J Mol Med Berl 91: 791-801, 2013.

14. Schmidt LH, Spieker T, Koschmieder S, Schäffers S, Humberg J, Jungen D, Bulk E, Hascher A, Wittmer D, Marra A, et al: The long noncoding MALAT-1 RNA indicates a poor prognosis in non-small cell lung cancer and induces migration and tumor growth. J Thorac Oncol 6: 1984-1992, 2011.

15. Li G, Zhang H, Wan X, Yang X, Zhu C, Wang A, He L, Miao R, Chen $\mathrm{S}$ and Zhao $\mathrm{H}$ : Long noncoding RNA plays a key role in metastasis and prognosis of hepatocellular carcinoma. Biomed Res Int 2014: 780521, 2014.

16. He Y, Meng XM, Huang C, Wu BM, Zhang L, Lv XW and Li J: Long noncoding RNAs: Novel insights into hepatocelluar carcinoma. Cancer Lett 344: 20-27, 2014.

17. Lai MC, Yang Z, Zhou L, Zhu QQ, Xie HY, Zhang F, Wu LM, Chen LM and Zheng SS: Long non-coding RNA MALAT-1 overexpression predicts tumor recurrence of hepatocellular carcinoma after liver transplantation. Med Oncol 29: 1810-1816, 2012.

18. Tsang WP, Ng EK, Ng SS, Jin H, Yu J, Sung JJ and Kwok TT: Oncofetal H19-derived miR-675 regulates tumor suppressor RB in human colorectal cancer. Carcinogenesis 31: 350-358, 2010.

19. Ariel I, Miao HQ, Ji XR, Schneider T, Roll D, de Groot N, Hochberg A and Ayesh S: Imprinted H19 oncofetal RNA is a candidate tumour marker for hepatocellular carcinoma. Mol Pathol 51: 21-25, 1998.
20. Lottin S, Vercoutter-Edouart AS, Adriaenssens E, Czeszak X, Lemoine J, Roudbaraki M, Coll J, Hondermarck H, Dugimont T and Curgy JJ: Thioredoxin post-transcriptional regulation by H19 provides a new function to mRNA-like non-coding RNA. Oncogene 21: 1625-1631, 2002.

21. Luo M, Li Z, Wang W, Zeng Y, Liu Z and Qiu J: Upregulated H19 contributes to bladder cancer cell proliferation by regulating ID2 expression. FEBS J 280: 1709-1716, 2013

22. Luo M, Li Z, Wang W, Zeng Y, Liu Z and Qiu J: Long non-coding RNA H19 increases bladder cancer metastasis by associating with EZH2 and inhibiting E-cadherin expression. Cancer Lett 333: 213-221, 2013.

23. Guo G, Kang Q, Chen Q, Chen Z, Wang J, Tan L and Chen JL: High expression of long non-coding RNA H19 is required for efficient tumorigenesis induced by Bcr-Abl oncogene. FEBS Lett 588: 1780-1786, 2014.

24. Emmrich S, Streltsov A,SchmidtF, Thangapandi VR, ReinhardtD and Klusmann JH: LincRNAs MONC and MIR100HG act as oncogenes in acute megakaryoblastic leukemia. Mol Cancer 13: 171,2014

25. Bennett JM, Catovsky D, Daniel MT, Flandrin G, Galton DA, Gralnick HR and Sultan C: Proposals for the classification of the acute leukaemias. French-American-British (FAB) co-operative group. Br J Haematol 33: 451-458, 1976.

26. Yu G, Yao W, Wang J, Ma X, Xiao W, Li H, Xia D, Yang Y, Deng K, Xiao H, et al: LncRNAs expression signatures of renal clear cell carcinoma revealed by microarray. PLoS One 7: e42377, 2012.

27. Prensner JR and Chinnaiyan AM: The emergence of lncRNAs in cancer biology. Cancer Discov 1: 391-407, 2011.

28. Li J, Chen Z, Tian L, Zhou C, He MY, Gao Y, Wang S, Zhou F, Shi S, Feng X, et al: LncRNA profile study reveals a three-lncRNA signature associated with the survival of patients with oesophageal squamous cell carcinoma. Gut 63: 1700-1710, 2014.

29. Yang F, Zhang L, Huo XS, Yuan JH, Xu D, Yuan SX, Zhu N, Zhou WP, Yang GS, Wang YZ, et al: Long noncoding RNA high expression in hepatocellular carcinoma facilitates tumor growth through enhancer of zeste homolog 2 in humans. Hepatology 54: $1679-1689,2011$ 